\title{
SpaceX Dragon Air Circulation System
}

\author{
Brenda J. Hernandez ${ }^{1}$ and Siarhei Piatrovich ${ }^{2}$ \\ Space Exploration Technologies, Hawthorne, CA, 90250 \\ Mauro Prina ${ }^{3}$ \\ Space Exploration Technologies, Hawthorne, CA, 90250
}

The Dragon capsule is a reusable vehicle being developed by Space Exploration Technologies (SpaceX) that will provide commercial cargo transportation to the International Space Station (ISS). Dragon is designed to be a habitable module while it is berthed to ISS. As such, the Dragon Environmental Control System (ECS) consists of pressure control and pressure equalization, air sampling, fire detection, illumination, and an air circulation system. The air circulation system prevents pockets of stagnant air in Dragon that can be hazardous to the ISS crew. In addition, through the inter-module duct, the air circulation system provides fresh air from ISS into Dragon. To utilize the maximum volume of Dragon for cargo packaging, the Dragon ECS air circulation system is designed around cargo rack optimization. At the same time, the air circulation system is designed to meet the National Aeronautics Space Administration (NASA) inter-module and intra-module ventilation requirements and acoustic requirements. A flight like configuration of the Dragon capsule including the air circulation system was recently assembled for testing to assess the design for inter-module and intra-module ventilation and acoustics. The testing included the Dragon capsule, and flight configuration in the pressure section with cargo racks, lockers, all of the air circulation components, and acoustic treatment. The air circulation test was also used to verify the Computational Fluid Dynamics (CFD) model of the Dragon capsule. The CFD model included the same Dragon internal geometry that was assembled for the test. This paper will describe the Dragon air circulation system design which has been verified by testing the system and with CFD analysis.

\section{Nomenclature}

$\begin{array}{ll}E C S & =\text { Environmental Control System } \\ I S S & =\text { International Space Station } \\ C F D & =\text { Computational Fluid Dynamics } \\ C O T S & =\text { Commercial Orbital Transportation Services } \\ T P S & =\text { Thermal Protection System } \\ I M V & =\text { Inter-Module Ventilation Duct } \\ S P L & =\text { Sound Pressure Limit } \\ N C & =\text { Noise Criterion } \\ P F E & =\text { Portable Fire Extinguisher }\end{array}$

\footnotetext{
${ }^{1}$ ECS Environmental Control System Engineer, Thermal, 1 Rocket Road Hawthorn, CA, and AIAA Member Grade for first author.

${ }^{2}$ Environmental Control System Engineer, Thermal, 1 Rocket Road Hawthorn, CA, and AIAA Member Grade for second author.

${ }^{3}$ Thermal Dynamics Manager, 1 Rocket Road Hawthorn, CA, and AIAA Member Grade for third author.
} 


\section{Introduction}

$\mathrm{D}$ ragon is a commercially developed reusable capsule developed by SpaceX under NASA's Commercial Orbital Transportation Services (COTS) to deliver cargo to and from the International Space Station. Dragon consists of a capsule with pressurized section and an unpressurized service section for cargo and avionics, a trunk with a radiator and deploying solar array, and a nose cone to protect the ISS berthing ring during ascent. Figure 1 shows the $1^{\text {st }}$ demonstration Dragon that flew in a low Earth orbit in December 2010. The service section has the Dragon propulsion system and avionics. The pressurized section contains avionics boxes, powered cargo and unpowered cargo. The entire pressure section and service section is covered with thermal protection system (TPS) for insulation. The Dragon air circulation system includes a fan, ducting, inlet and outlet vents, air to liquid heat exchanger, accommodation for powered cargo and smoke detectors. Additionally, the air circulation system was designed with consideration for noise and includes acoustic treatment to reduce air borne noise. The air circulation system test and CFD correlation and the acoustics testing are discussed herein.

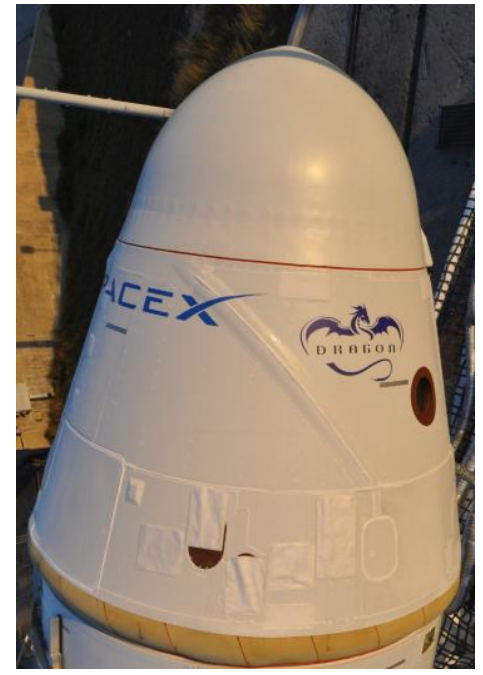

Figure 1.Dragon

\section{Dragon Pressure Section}

As a cargo carrying vehicle, Dragon is capable of delivering $6000 \mathrm{~kg}$ of cargo to ISS and bring back $3000 \mathrm{~kg}$ to earth. For this reason the pressure section is mainly occupied by racks to hold cargo. There are a total of 9 cargo racks in Dragon. These include the floor deck that has lockers for storage, the aft rack, the starboard rack, the port rack, and the 4 late load racks. Figure 2 shows the interior of dragon with all the cargo rack except the port rack for clarity.
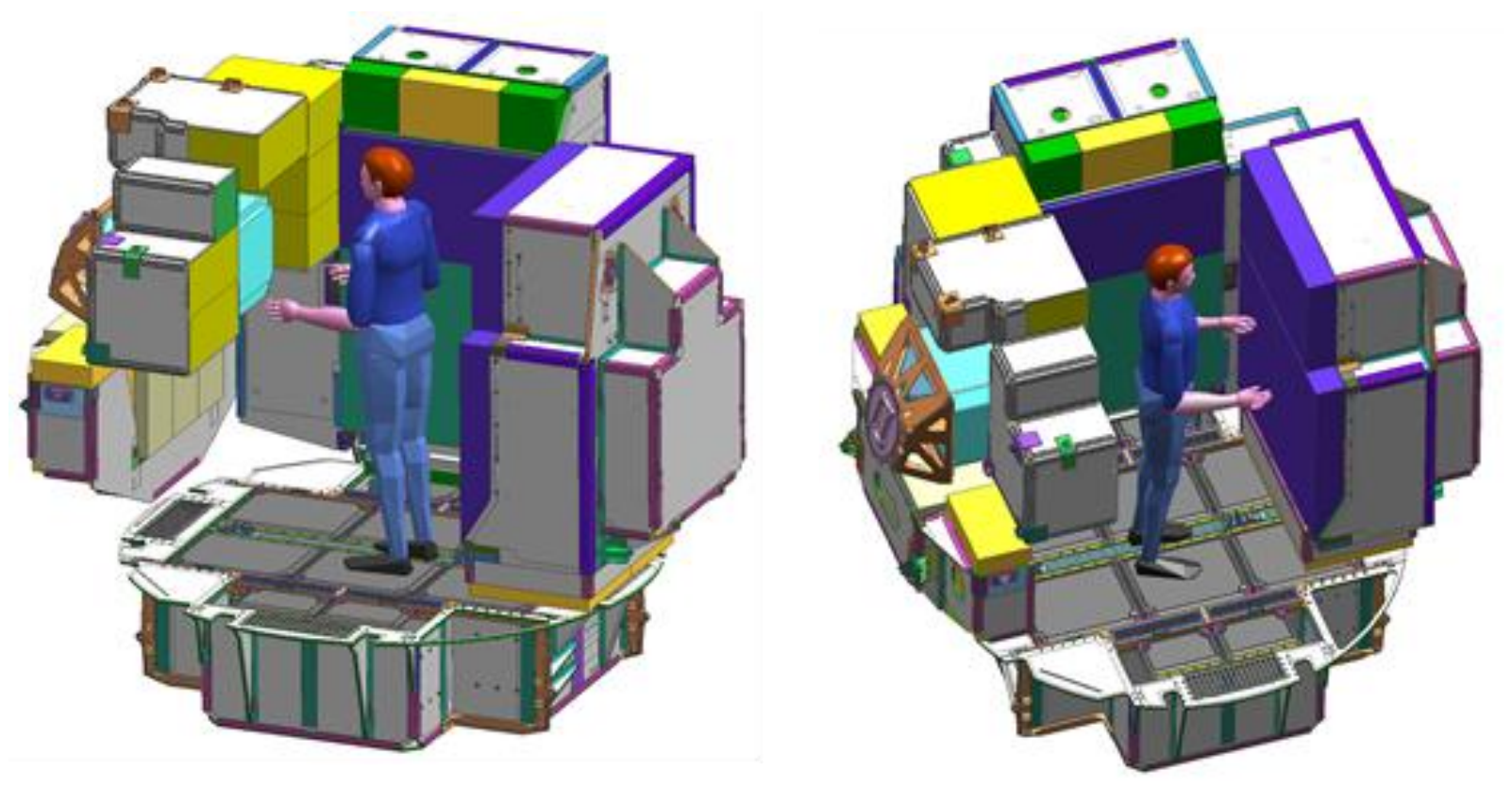

Figure 2. Dragon Pressure Section Cargo Racks. 
As is seen from figure 2, it is necessary to have an air circulation system that not only meets all the necessary requirements, but is also capable of providing enough pressure given the allotted volume for the air duct and in consideration of the fact that the capsule will be filled with avionics boxes, cargo and cargo racks that constrain air flow. The air circulation system consists of a fan, an air duct with inlet vents, an inter-module ventilation duct to provide fresh air to Dragon from ISS, air outlets on the floor rack, and a suite of sensors. Additionally, recommendations were given for the cargo racks to have holes for air circulation purposes. Figure 3 shows the starboard rack with ventilation holes and each rack also has large ventilations holes that match the outlet vents on the floor in order to have air move from the floor vent to the inside of the cargo rack and to the center of the cabin.

Ultimately, the air circulation system was designed to provide a quiet and fresh air environment to the working crew inside the module. The derived requirements are captured in SSP 50808 COTS-ISS Interface Requirement Document for intra-module ventilation and inter-module ventilation ${ }^{1}$. Air moving through the duct and air being pushed by the fan blades, naturally create noise that can be fairly loud. To maintain reasonable sound levels in the cabin, the environmental control system was treated with acoustics insulation to meet the NASA noise requirements.

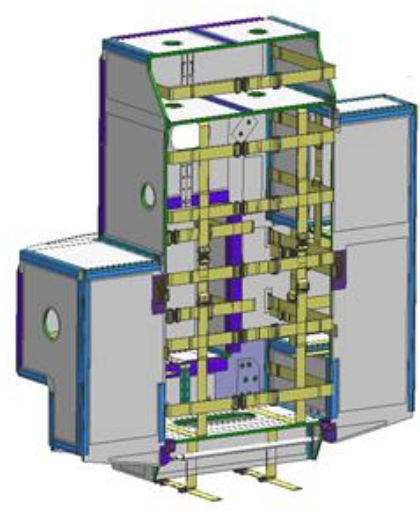

Figure 3. Starboard Cargo Rack

\section{A. Air Circulation Requirements \& Habitability}

Dragon is a cargo carrying capsule that requires ISS crew to be able to load and unload cargo comfortably. For this reason, there are habitability requirements for air circulation inside Dragon, inter-module ventilation to provide fresh air from ISS and to limit noise (SSP 50808 COTS-ISS Interface Requirement Document ${ }^{1}$ ).

\section{Air Flow}

There are inter and intra vehicle atmosphere requirements that were verified with testing and analysis. The air flow requirements ensure that the crew has ventilation that is comfortable while they unload and load cargo and also that they are provided with sufficient fresh air from the ISS. Dragon does not have $\mathrm{CO}_{2}$ removal equipment such as $\mathrm{LiOH}$ and therefore relies on ISS for $\mathrm{CO}_{2}$ scrubbing. The Inter-module Ventilation duct (IMV) connects from Dragon to ISS to provide fresh air in Dragon. The specific requirements that ensure adequate ventilation and delivery of fresh air are described below

a. Atmosphere Circulation

b. Inter-module Atmosphere Receive Rate
For cargo variants of Dragon, the air velocity through 2/3 of the internal cabin habitable volume excluding the layer 6 inches from the cabin aisle way surfaces shall be between $10 \mathrm{feet} / \mathrm{min}$ and $40 \mathrm{feet} / \mathrm{min}$. To avoid pockets of stagnant air, air velocities outside the layer 6 inches from the cabin aisle way surfaces averaging less than 7 feet/min shall not sum to equal a volume larger than $5 \%$ of the total internal cabin volume (schematic representation in Figure 4).

The IMV volumetric flow shall be maintained between 135 and 210 cubic feet/min for normal operation with the COTS vehicle hatch open.

3

American Institute of Aeronautics and Astronautics 


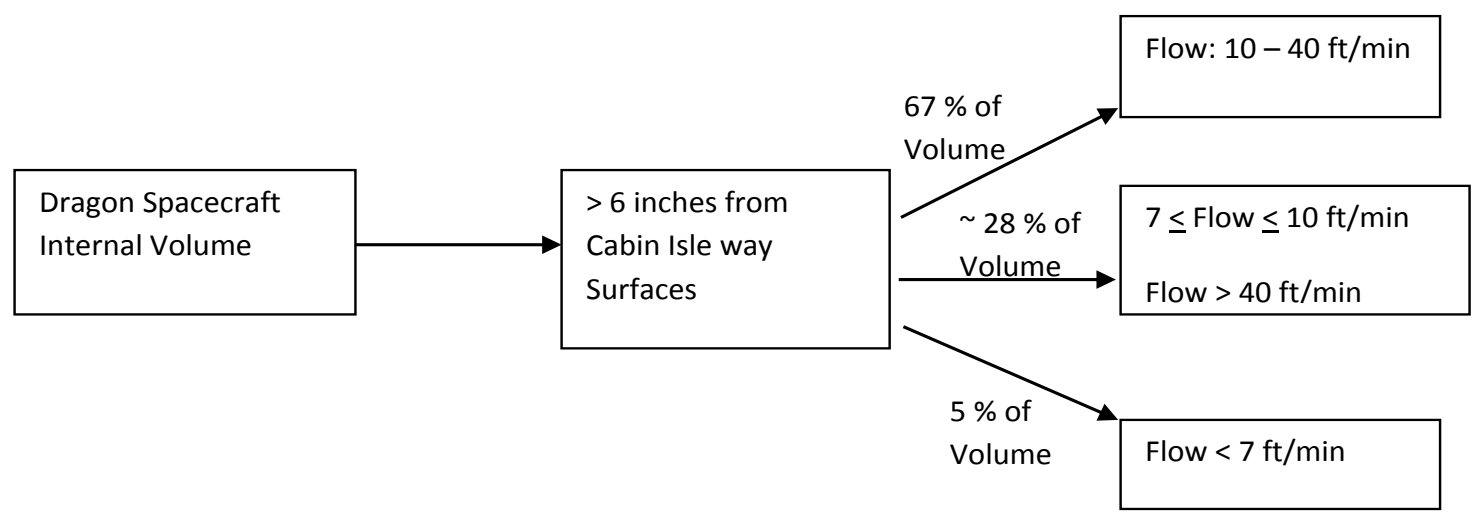

\section{Figure 4. Intra-Vehicle Circulation Requirement}

\section{Acoustics Requirements}

The acoustics environment was evaluated with testing to show the ISS crew is able to hear each other while inside Dragon as well as the ISS alarms in case of an emergency. Additionally, the acoustic noise at the IMV duct was evaluated to ensure that the noise in Node 2 and in the proximity to where the ISS crew sleeping quarters are located was acceptable. Inside Dragon the noise criterion is NC-50 which is comparable to the noise down an office hallway. The noise outside Dragon in Node 2 due to the inter-module ventilation duct must be at or below NC-40 which is comparable to noise in a library. These requirements allow for adequate habitability while working inside Dragon.

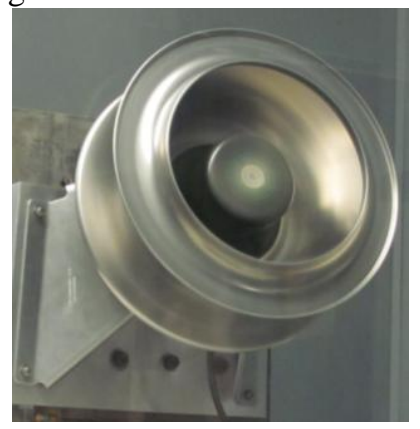

Figure 5. Air Circulation Fan

\section{B. Air Circulation System Accommodation in the Pressure Section}

The air circulation system in Dragon is provided by a fan (Figure 5) that can delivers over 400 CFM to maintain the required air speeds inside the capsule while sucking sufficient air from the IMV duct. The fan can be power at different speeds to provide up to 1800 CFM at relatively low noise levels. Having the option of varying the fan speed allows the freedom to tune in air flow and noise levels on the system to keep the system within the reasonable boundaries set by the constrains aforementioned.

The fan is mounted to the Dragon forward wall structure above the floor rack and has a shroud that surrounds its outlet and an inlet. The duct leading to the floor opens up into a larger area where a suite of sensors reside. Figure 6 shows Dragon capsule model with structure removed to show the cargo racks, floor, and duct. Figure 7 shows Dragon capsule model with the racks removed to show the duct and the floor with outlet vents more clearly. 


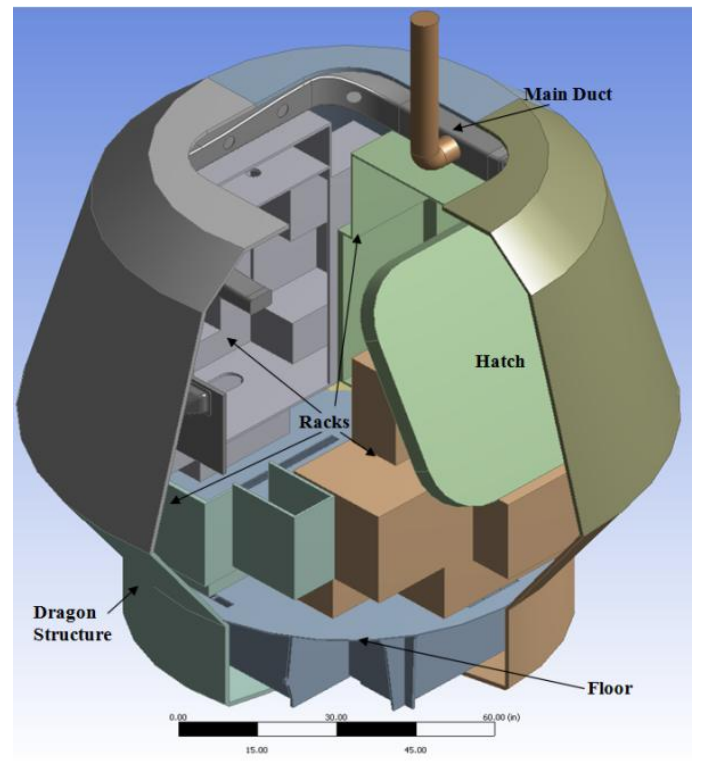

Figure 6. Dragon capsule model with the Structure removed.

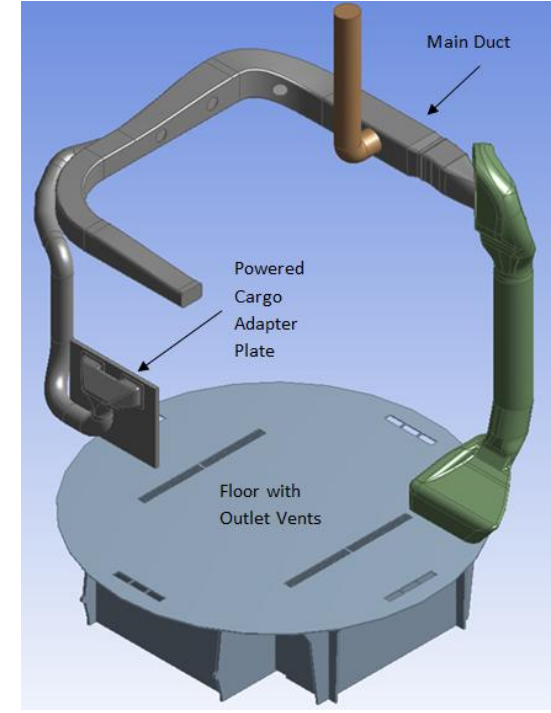

\section{Figure 7. Dragon capsule with Structure \& Cargo Removed}

The plenum under the floor is defined by the perimeter of the basement lockers, the floor, and the cylindrical Dragon walls underneath the floor. Air from the plenum is then pushed up to the cabin through air circulation vents on the floor (Figure 7).

The floor has a total of eight outlet vents. Four outlet vents are located along the perimeter of the floor, with one outlet vent underneath the structure of each main rack (Aft, Forward, Starboard, and Port) and four additional vents are located in the center of the floor (Figure 8). For the ISS crew comfort, the air is pushed up to the floor vents in potential locations where the crew can be loading and unloading cargo.

In the cabin, as the air moves upward, some of the air returns to the main duct through inlet vents (Figure 9) that then takes the air back to the fan. The rest of the air mixes with Node 2 air through the open hatch. There are 3 inches

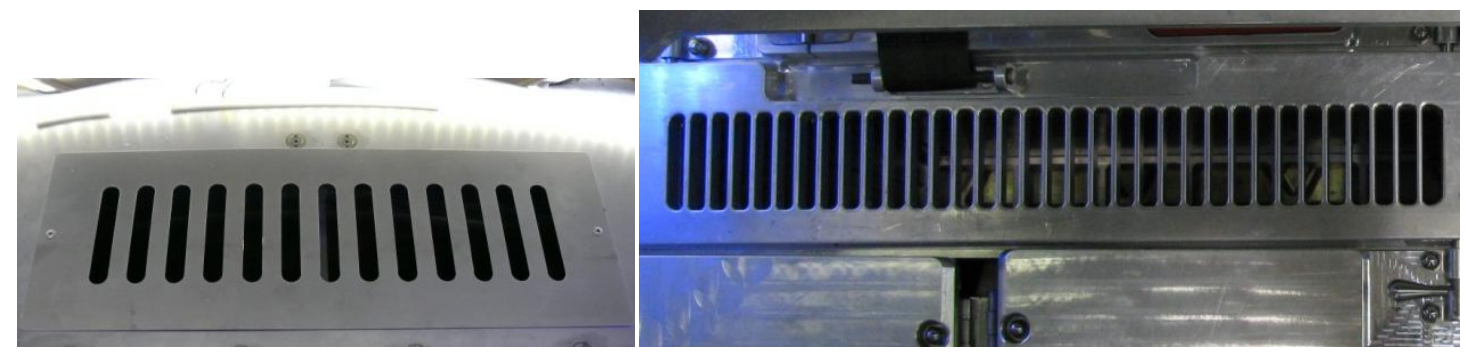

Figure 8. Outlet Vents on the Floor

inlet diameter vents along the main duct. Also, the main duct is connected to the powered cargo adapter plate through a 4 inches diameter duct. When powered cargo is removed the inlets on the adapter plate suck air from the pressure section into the main duct. The main duct inlet vents and the powered cargo inlet vents are lined with a fine wire mesh. In addition to this fine wire mesh, the inlet vents have a rock catching screen with wide screen holes (Figure 9).

The IMV duct is connected to the Dragon main duct and to the ISS air circulation system to provide fresh air in Dragon. Connecting the IMV will be one of the 1st steps done during ingress. This duct will be provided by SpaceX and is a 5" diameter duct that connects to the Aft side of the main duct and in close proximity to the fan. Figure 9 


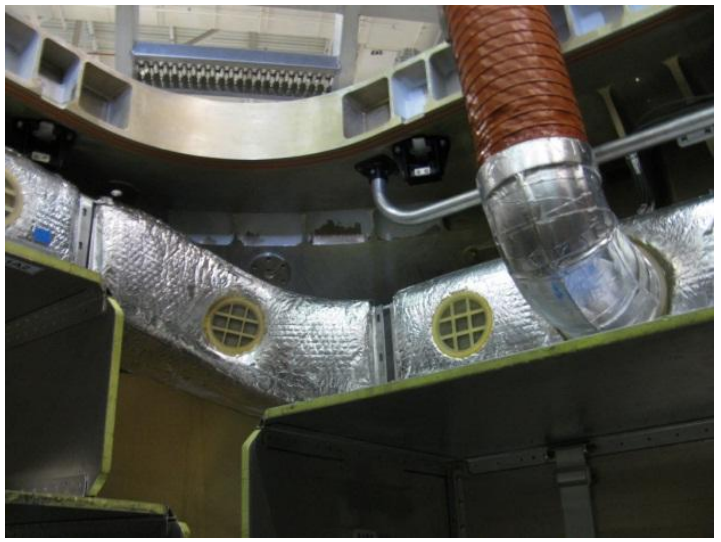

Figure 9. View of Duct with Inlet Vents Inside Dragon Pressure Section

shows a picture of the IMV. On the Node 2 side it will be mated using a V-band clamp and on the Dragon side, it is mated with a quick connection. The aft side of the main duct has a latching door that can be simply opened with the tabs at the end of the IMV.

In case of a fire while berthed to ISS, the crew will extinguish the fire with a portable fire extinguisher (PFE). Two sources of fire are the fan and the powered cargo. Both of these are along the air circulation duct and as such, there is a PFE port placed on the duct and approximately a foot away from the fan so that when the PFE is fired the $\mathrm{CO}_{2}$ goes directly to these fire sources. CFD analysis has shown that it would take 10 seconds to extinguish a fire at the powered cargo and less than that to extinguish a fire at the fan.

The Dragon ECS also has a suite of sensors. The sensors that pertain to the air circulation system are temperature sensors, humidity sensors and smoke detectors. These are all within the duct or in close proximity to the duct to make sure they are in the air flow stream. Using CFD, it was verified that downstream from the fan and before reaching the plenum below the floor, there is a good air flow stream. Therefore, the 2 smoke detectors and 2 humidity \& temperature sensors reside at this location and an additional humidity sensor and temperature sensor was placed upstream of the fan.

The smoke detector is functional in natural-convection since it is a photoelectric device that uses light scattering effect to determine if there is smoke. When a beam of light passes through a space occupied by the smoke particles, the incident light (generated by the smoke detector) will be scattered off from the axis of the projected light beam. The intensity of this light scatter will trigger a smoke alarm. In addition to having the ability to detect smoke, the detector also does a self-health check and reports health

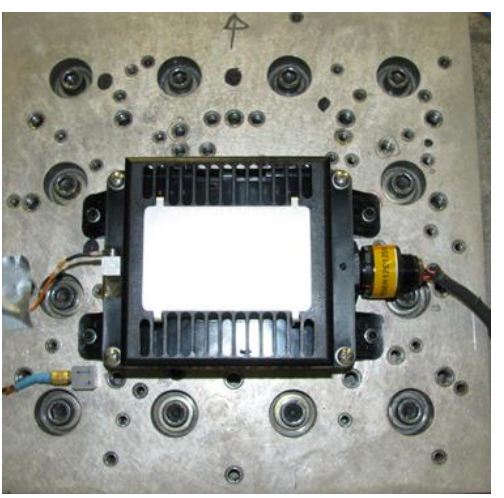

Figure 10. Dragon Smoke Detector Unit and whether smoke has been detected. A fire alarm will be announced when a detector is healthy and has detected smoke. Figure 10 shows the two smoke detectors in one box going through flight qualification.

\section{Acoustics Considerations}

The air circulation system that provides the required atmosphere inherently creates an acoustic environment and consideration of this was included in the design to allow the crew to work continuously in a safe and quiet environment, as captured by the NASA acoustic requirements ${ }^{1}$. The acoustics environment established by the required air flow has been evaluated inside Dragon and at the IMV inlet.

The primary item taken into consideration from an acoustics standpoint was the fan. The Dragon fan generates maximum sound at lower frequencies and is quieter at higher frequencies $(69 \mathrm{dBA}$ when operating at maximum power and providing $1800 \mathrm{CFM}$ ). The fan is mounted on isolators to reduce vibration. Since it is not required that the fan be used at its maximum power because the necessary volumetric flow rate is less than the capability of this fan, the noise level is naturally lower but not sufficient to meet the required specification. Therefore, the air duct has been acoustically treated, as well as the floor, and the capsule walls. The part that received more attention is the fan shroud, where the source of noise is located. 


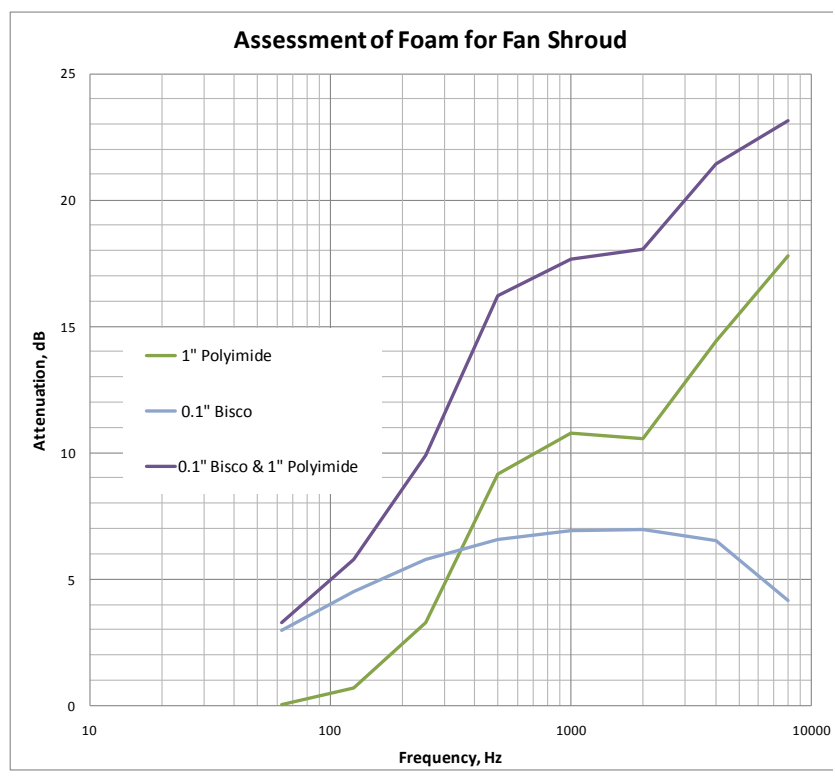

Figure 11. Assessment of Various Acoustic Foam Layup on Fan Shroud/Inlet
The acoustic treatment design on the shroud \& inlet was done using a material with high transmission loss and also good absorption. The sizing of the acoustic treatment was accomplished using a VAOne component level model to assess the attenuation of different materials. The VAOne model consisted of a source cavity and a receiver cavity separated by a partition. The partition could be varied in material properties, thickness and even a layup of several different types of materials could also be created. Prior to running the VAOne model, sound pressure level measurements were taken with a sound level meter at the fan and these measurements were used at the source cavity in the VAOne model. This model was not used to assess the absolute noise of the fan but to assess how the acoustic treatment of the shroud could be selected and sized. The materials assessed were Bisco sound blocker and polyimide open-cell foam as have been evaluated in past studies for the ISS crew sleeping quarters ${ }^{2}$. Several thicknesses of the Bisco and polyimide foam were compared taking into consideration the space around

the shroud for foam. The plot in Figure 11 shows three of the many configurations that were considered. This plot shows that considering the available space around the fan shroud, the optimal solution is to have 1" of Polyimide foam and at least 0.1 " of Bisco on the exterior of the fan shroud. The sound blocking Bisco reduces transmissibility of the noise generated by the fan, and the open cell foam was used for absorption. The sound blocker and open cell foam were placed on the exterior of the

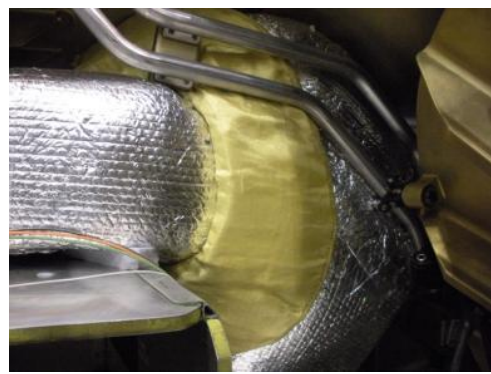

Figure 13. Fan Acoustic Blanket shroud and fan inlet cover in order to not interfere with the air flow inside. The exterior of the rest of the duct was lined with $1 "$

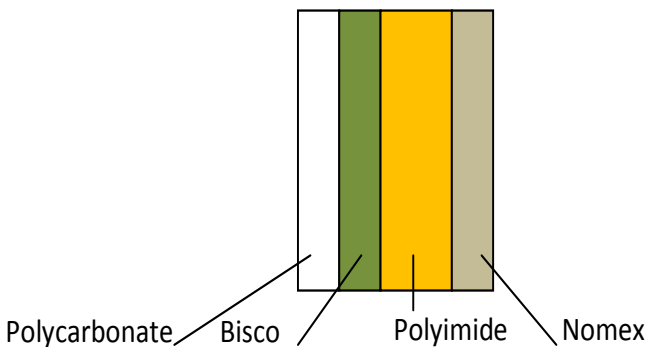

Figure 12. Foam Layers on Fan Shroud and Inlet Cover

of polyimide foam to reduce air born noise inside the duct. Figure 12 shows the layers of the Bisco and polyimide foam on the fan shroud and inlet that will be used for flight.

In addition to treating the fan shroud and inlet acoustically, there is an acoustic blanket placed over the inlet cover (the area between the fan inlet \& shroud). For testing, the blanket was made with Bisco (1.0 psf) and polyimide foam, and Kevlar was used to encapsulate the polyimide foam, as shown in Figure 13. For flight, the Kevlar will be replaced with Nomex for materials \& processing purposes.

As discussed previously, the air pushed by the fan creates a plenum underneath the floor. The bottom side of the floor was lined with 1" thick polyimide foam to absorb noise coming from the air flow in the plenum. The flight unit consists of an aluminum honeycomb floor and any gaps between the floor and the Dragon structure will be sealed with polyimide foam as well.

Additionally, the Dragon walls were lined with 1" thick polyimide foam to increase the reverberation time in order to reduce echo inside the capsule. Polyimide foam was selected due to its absorptive acoustic properties and since it is acceptable by NASA material standards.

\section{Air Circulation System Development Testing}

The ventilation and acoustics testing of the air circulation system were done with the same test set up and configuration. The set up was done inside the Dragon qualification unit that has the same structure as the Dragon that will go to ISS and included all the flight like interior components necessary for these tests. The Dragon pressure section was fitted with flight like cargo racks, an aluminum honeycomb panel floor with basement lockers and outlet 
vents, an air duct with inlet vents, a fan, accommodation for the powered cargo and the stowed forward hatch. As in the flight configuration, the fan was mounted above the floor with a shroud at the outlet, the duct leading to the floor opens up into a larger area. Figure 6 previously discussed shows Dragon with structure removed to show the cargo racks, floor, and duct.

The floor included the eight flight-like outlet vents and was supported by beams that were connected to the isogrid structure underneath the floor. Foam was placed in the gaps between the floor and the Dragon structure to prevent air and noise from leaking out from underneath the floor as in the flight unit. Foam was also placed underneath the floor surface. The side hatch was closed and included the powered cargo adaptor plate. The test setup simulated an empty Dragon case with the powered cargo removed.

This test configuration also included the IMV prototype duct and latching door to simulate inter-module ventilation from ISS Node 2.

\section{CFD Model}

The CFD model includes all of the items that are part of the Dragon capsule, such as the Dragon structure, floor with outlet vents, main air duct with inlet vents, fan, plenum, all of the cargo racks, and the powered cargo adapter duct. The purpose of the Air Circulation CFD model is to analyze the Dragon capsule air circulation with all appropriate hardware. The CFD model was correlated against the test air speed spot checks using the same configuration. Additionally, the CFD model results are used as a method of choosing locations for air speed spot checks on the vehicle. Now that the CFD model is correlated, the model is used for verification of the air circulation requirements and for air flow predictions of the Dragon capsule air circulation system with additional hardware, such as cold plates with avionics boxes, various passive cargo configurations, etc. The description of the air circulation CFD model that was used to correlate with testing is provided below.

The CFD model geometry represents Dragon capsule test configuration and includes flow-critical elements, such as cabin interior surfaces, cabin floor with 8 outlet vents, cargo racks, forward hatch opening, main duct with inlet vents, powered cargo adapter plate, IMV duct and forward hatch (Figure 6). The duct inlet vents are modeled as openings in the duct, and the floor vents are modeled as openings in the floor (Figure 14). It is ensured that there are no air leaks between the plenum under the

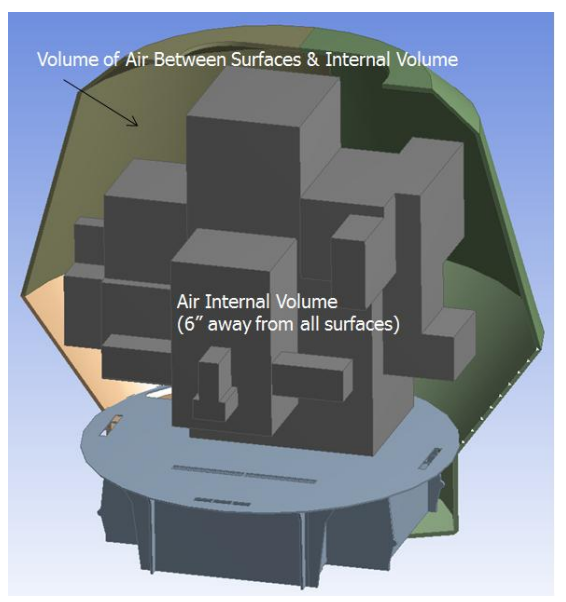

Figure 14. Internal Volume 6" Away from Surfaces floor and the interior Dragon volume, other than through the floor vents.

In order to verify the results of the CFD model against air speed requirements inside the Dragon internal volume, a volume within the Dragon model was created to represent the volume 6" away from all internal surfaces (Figure 15). This volume was later used to create a histogram showing the volume percent at different speeds.

The CFD model geometry creates an enclosed volume of air. This volume was used for the CFD meshing and simulation using ANSYS CFX. The air volume mesh contains over a million elements, with maximum element characteristic length of $0.10 \mathrm{~m}$, and minimum characteristic length of $.003 \mathrm{~m}$ (Figure 16), with an average mesh quality greater than 0.8 and a standard deviation lower than 0.1 . Increased mesh resolution was used near internal surfaces and in highspeed flow regions where large velocity gradients are expected. The turbulence model used is k-epsilon, with scalable wall function. The formulation does not require resolution of viscous sub-layer, and is capable of properly handling flow separation regions. The boundary conditions were specified on the surfaces shown in Figure 17 at the fan, open hatch and IMV. The fan outlet was set to provide 465 CFM

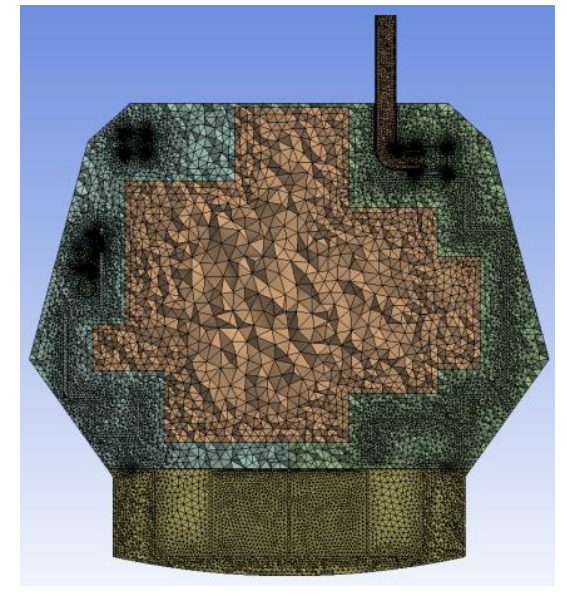

Figure 16. Air Volume Mesh 
volumetric flow by specifying the tangential and normal velocity. The volumetric flow rate set was the value observed during testing. The volumetric flow rate at the fan inlet is set to be equal to volumetric flow rate at the fan

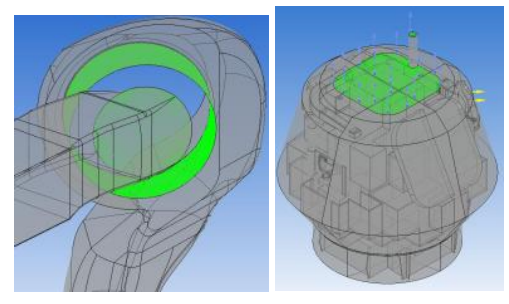

Figure 17. CFD Model Boundaries outlet. The total pressure at the IMV inlet and the environmental pressure at the hatch opening are set to 1 atm. Second order double precision turbulence solver with automatic pseudo time stepping was used to obtain the numerical solution. During the run, normalized residuals were monitored to measure local imbalances of the linearized system of equations at each control volume. The model was set to run for up to 1200 iterations, with a minimum convergence criterion. In addition, the static pressures at both fan inlet and outlet were monitored, and the run was stopped when the flow pressures on fan boundaries were stabilized.

\section{Air Circulation Test}

The purpose of testing the air circulation system was to correlate the CFD model. In order to correlate the model, air speed measurements were taken at specific locations. First, a volumetric flow balance was verified. Air speed and volumetric flow measurements were taken at all the outlets on the floor and all the inlets on the duct and IMV and at the inlet of the fan with two anemometers. For air speeds above $500 \mathrm{ft} / \mathrm{min}$, a 0-6000 ft/min anemometer was used and for air speeds below $500 \mathrm{ft} / \mathrm{min}$ an omnidirectional air speed transducer was used. Pressure was also taken at the fan inlet and the IMV with a 0 to 1 inch of water pressure gauge.

After the air balance was completed for a fan speed of $1200 \mathrm{rpm}$, it was determined that 465 CFM was delivered by the fan. The testing then involved taking air speeds spot checks in locations inside the cabin where the CFD indicated stability, in order to increase the chances of having precise measurements. The air speed spot checks were taken with the omnidirectional anemometer that read speeds between $0-100 \mathrm{ft} / \mathrm{min}$ and has an accuracy of $+/-3.0 \%$ of reading $\&+/-1.0 \%$ selected scale range.

The results of the CFD model simulation were compared to test measurements in the same Dragon capsule configuration. First, the volumetric flow rates were verified by performing air spot velocity measurements next to the floor outlet vents and main duct vents, respectively. The velocity measurements for each vent were averaged and multiplied by the vent area. The results of test-based volumetric flow rate calculation and their comparison to the CFD model predictions is shown in Table 1. As can be seen, the CFD model volumetric flow rate agrees well with the test measurements. This is to be expected, since the CFD model was ran at 465CFM based on preliminary test data.

The next step was to compare the volumetric flow rate predicted by CFD model through each of the floor outlets and each of the main duct inlets to the test measurements. The results of the comparison are shown in Table 2 for floor outlets and Table 3 for main duct inlets. The comparison shows that the CFD model gives at most a $+14 \% /-$ $15 \%$ error for the floor outlet vents compared to test data, and $+17 \% /-16 \%$ error for the main duct inlets. It should be

Table 1. Volume Flow Rate Balance

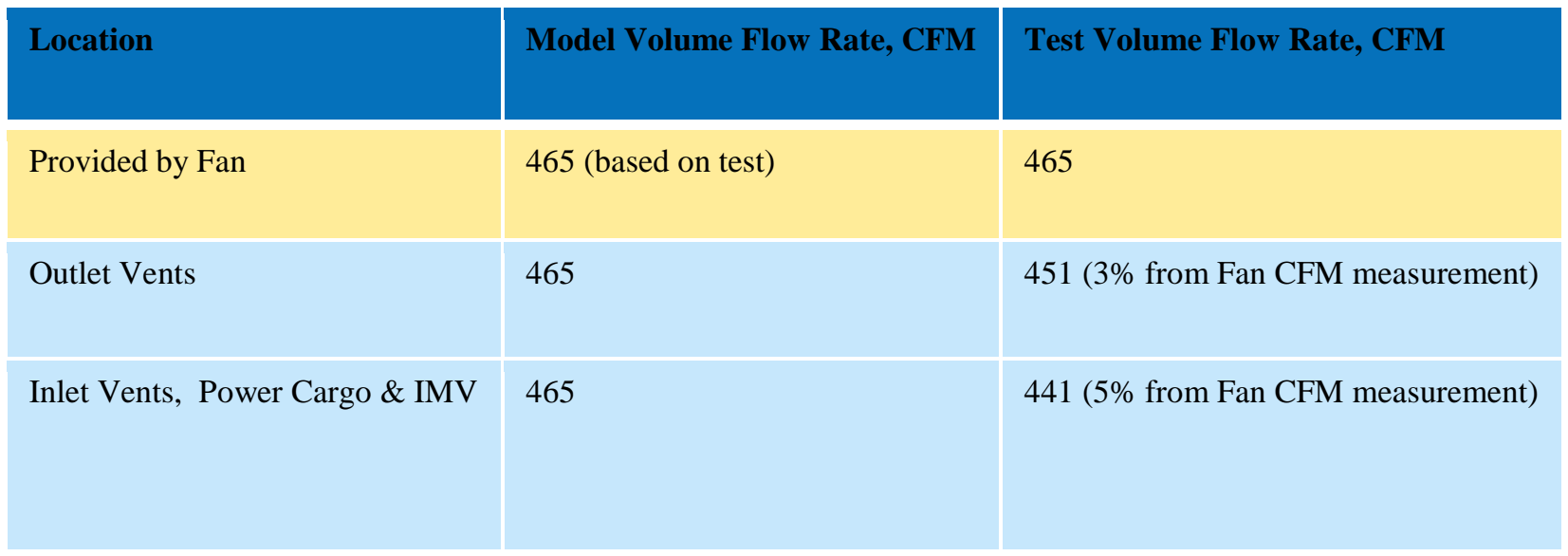

noted that the error related to the IMV duct flow rate is only $1 \%$. 
Table 2. Floor outlets volume flow rate comparison, CFD model vs test data.

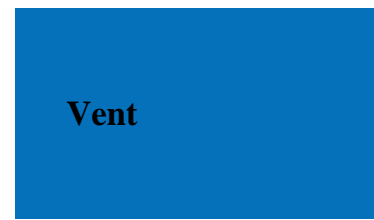

Model
Volume
Flow
Rate,
CFM

Test
Volume
Flow
Rate,
CFM

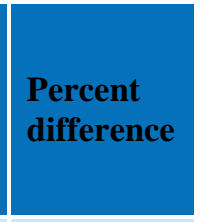

\begin{tabular}{|l|l|l|r|}
\hline Aft & 66 & 77 & $14 \%$ \\
\hline Starboard (Stb) & 60 & 52 & $-15 \%$ \\
\hline Forward & 60 & 54 & $-11 \%$ \\
\hline Port & 64 & 62 & $-3 \%$ \\
\hline Center Port Aft & 41 & 40 & $-3 \%$ \\
\hline Center Port Fwd & 56 & 55 & $-2 \%$ \\
\hline Center Stb Aft & 62 & 59 & $-5 \%$ \\
\hline Center Stb Fwd & 56 & 52 & $-8 \%$ \\
\hline
\end{tabular}

Of more interest are the model predictions of the velocities at different points inside the internal habitable volume, since these are related directly to the air speed requirements inside the capsule. Therefore, several contour plots of air velocities were extracted from the CFM model results at 1,3,5 and $6 \mathrm{ft}$ above the floor (Figure 18). These were compared to air spot measurement data taken at the same altitudes. Figure 19, Figure 20, Figure 21 and Figure 22 show contour plots of air velocities at different altitudes along with the test measurements. The points where velocity comparisons were made are labeled, and both CFD and measurements results along with standard deviation are shown. Most of the velocities from CFD results are within standard deviation of test measurements, except points $1 \mathrm{~B}, 3 \mathrm{D}, 5 \mathrm{~A}, 5 \mathrm{C}$ and $6 \mathrm{~A}$, which are within two standard deviations.
Table 3. Main duct inlets volume flow rate comparison, CFD model vs test data

\begin{tabular}{|c|l|l|l|}
\hline Vent & $\begin{array}{l}\text { Model } \\
\text { Volume } \\
\text { Flow Rate, } \\
\text { CFM }\end{array}$ & $\begin{array}{l}\text { Test } \\
\text { Volume } \\
\text { Flow Rate, } \\
\text { CFM }\end{array}$ & $\begin{array}{l}\text { Percent } \\
\text { difference }\end{array}$ \\
\hline IMV & 150 & 149 & $-1 \%$ \\
\hline 2 & 43 & 43 & $0 \%$ \\
\hline 3 & 46 & 43 & $-7 \%$ \\
\hline 4 & 43 & 40 & $-8 \%$ \\
\hline 5 & 40 & 41 & $2 \%$ \\
\hline 6 & 31 & 31 & $17 \%$ \\
\hline 7 & 25 & 30 & $12 \%$ \\
\hline 8 & 22 & 25 & $-16 \%$ \\
\hline Powered & 44 & 38 & \\
\hline Cargo & & & \\
\hline
\end{tabular}

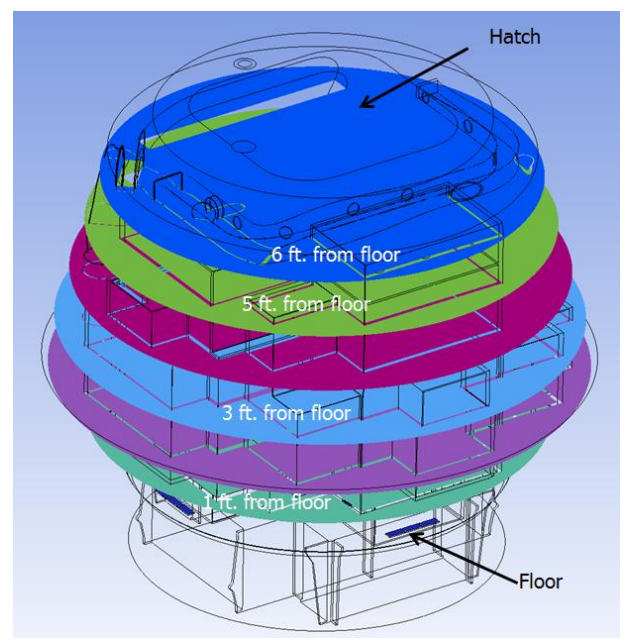

Figure 18. Elevation above the floor at which velocity contour plots were extracted 


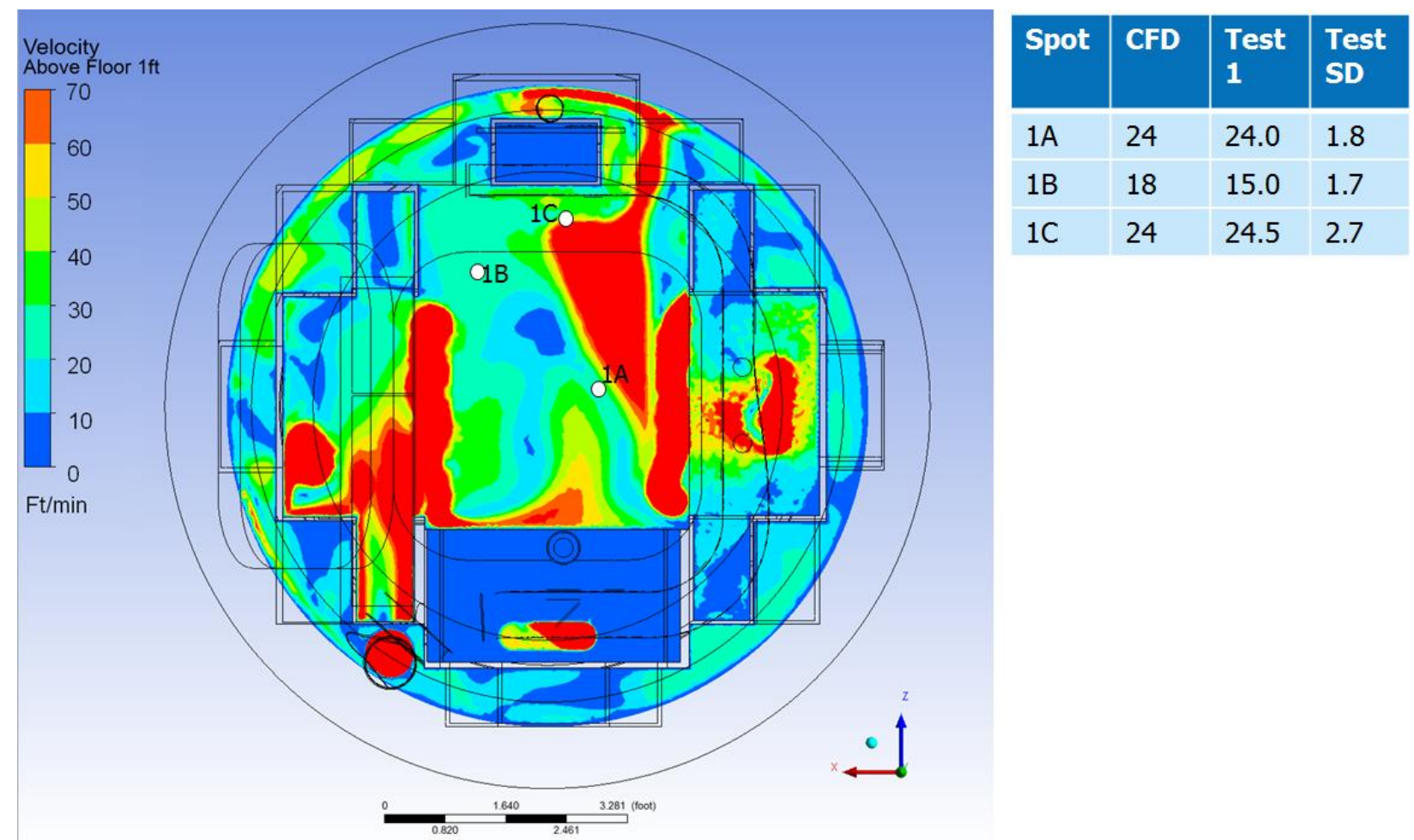

Figure 19. Velocity contour and air spot check comparison at $\mathbf{1 f t}$ above the floor

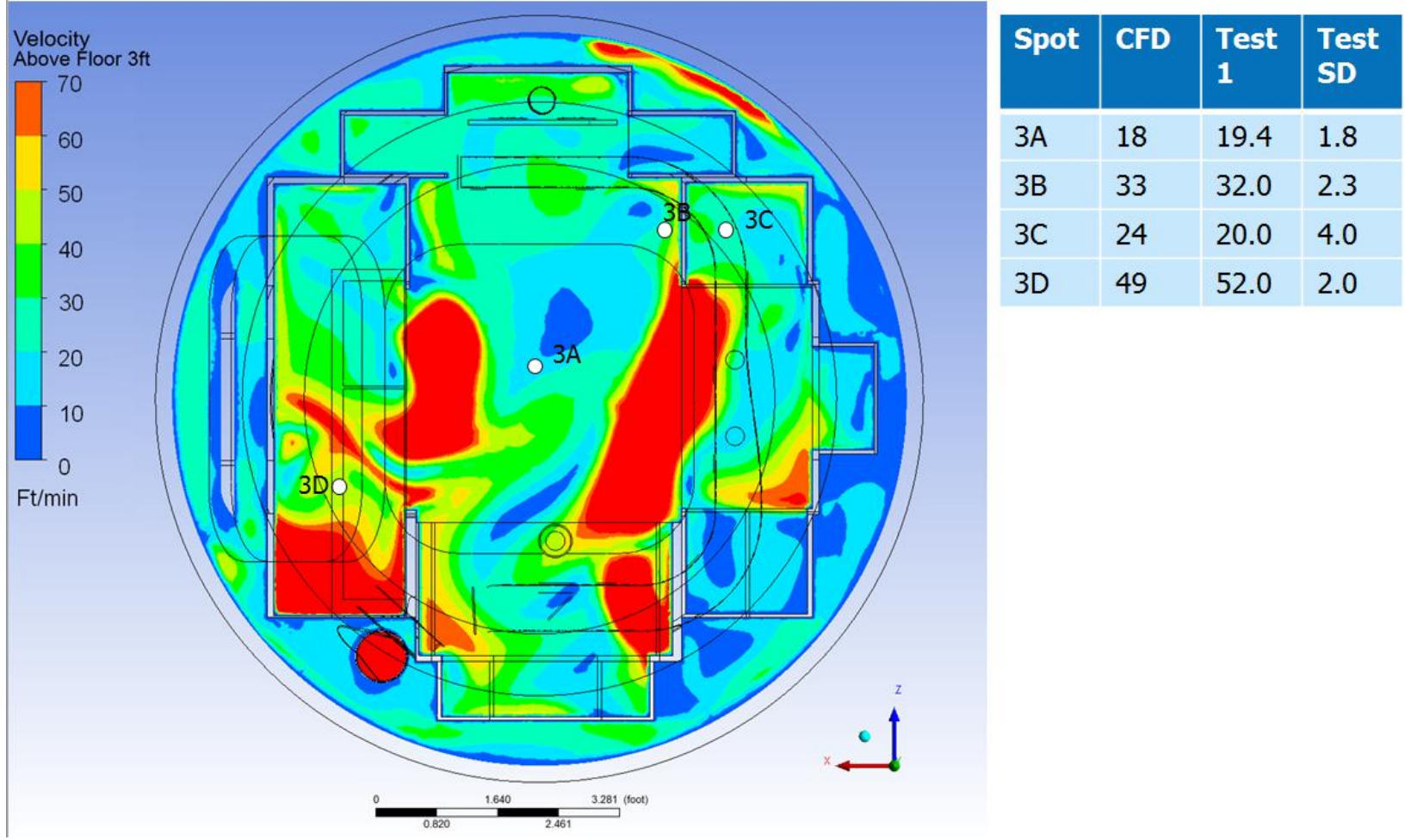

Figure 20. Velocity contour and air spot check comparison at $3 \mathrm{ft}$ above the floor 


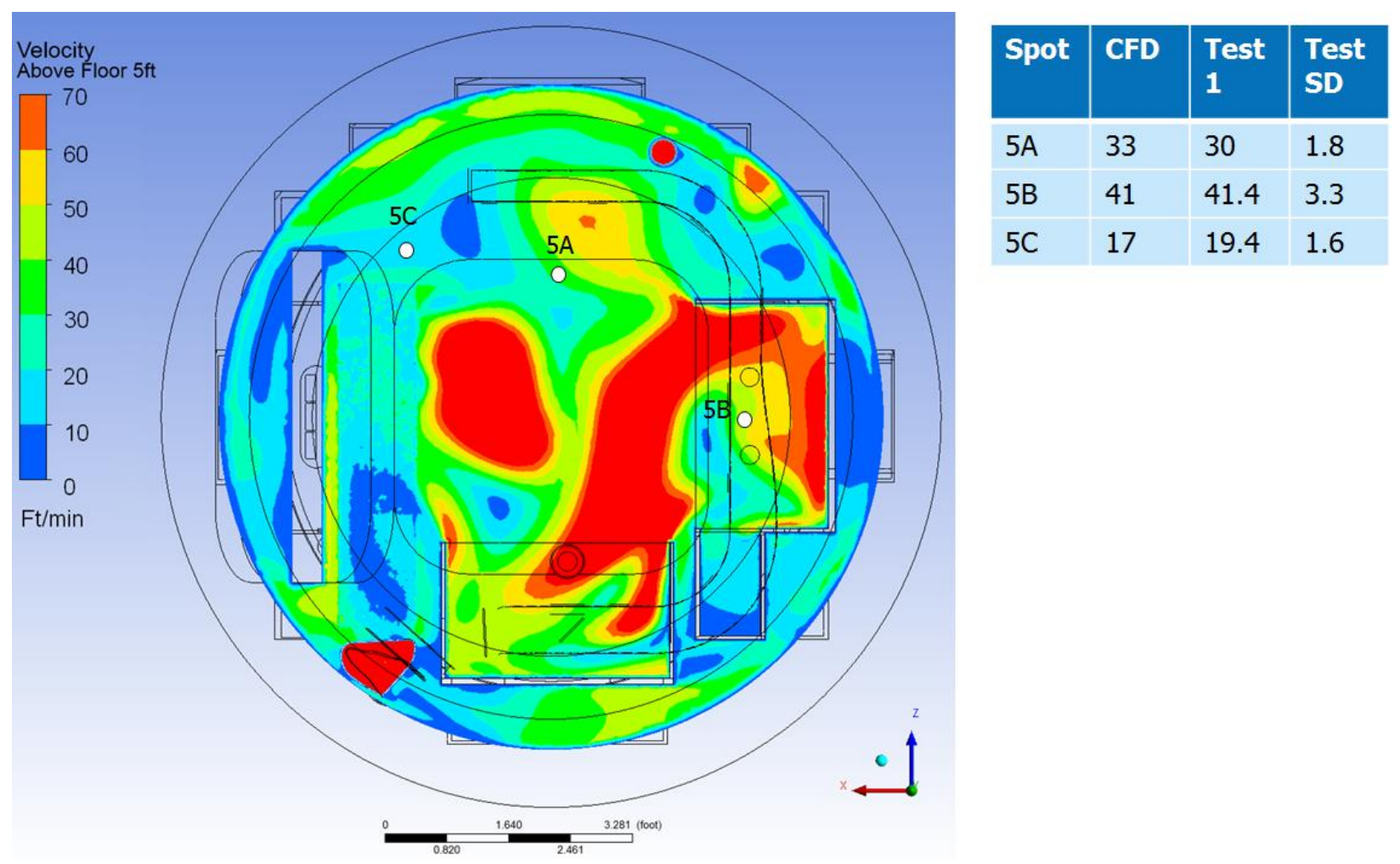

Figure 21. Velocity contour and air spot check comparison at $5 \mathrm{ft}$ above the floor

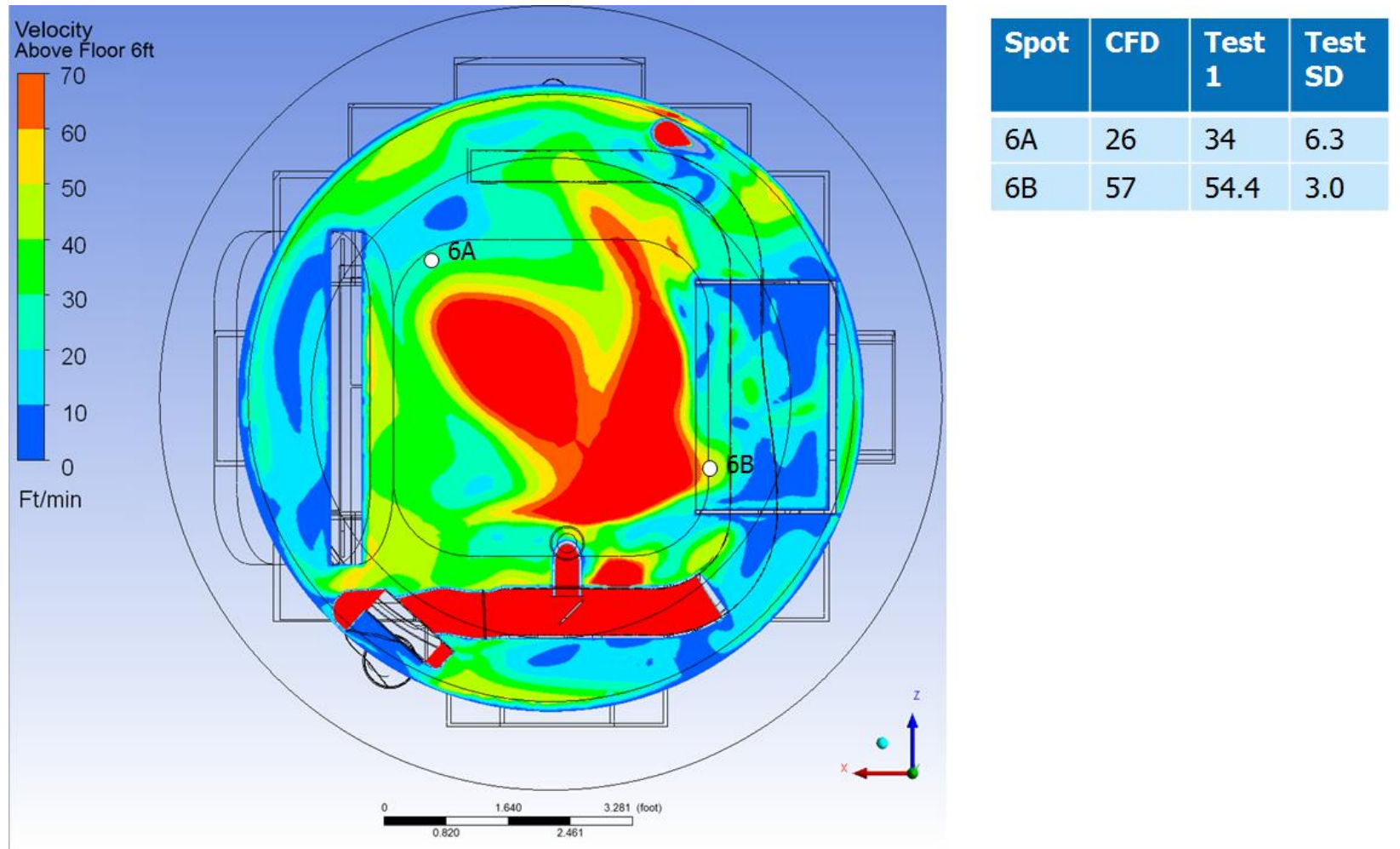

Figure 22. Velocity contour and air spot check comparison at $6 \mathrm{ft}$ above the floor 
Based on the comparison of the CFD model results to test measurements, the CFD model was deemed sufficiently correlated to the test data, and as such was used for air distribution calculation and requirement verification. Figure 23 shows the histogram of volumetric air velocity distribution inside the 6" interior volume. The regions of velocity in the range $0-7 \mathrm{ft} / \mathrm{min}$ occupy only $1 \%$ of internal flow, thus eliminating threat of pockets of stagnant air inside the capsule. Most of the volume (74\%) has velocities between 10 and $70 \mathrm{ft} / \mathrm{min}$ which is acceptable because according to the American Society of Heating, Refrigeration and Air Conditioning Engineers (ASHRAE) standards for human comfort, the majority of humans are comfortable up to $250 \mathrm{ft} / \mathrm{min}$.

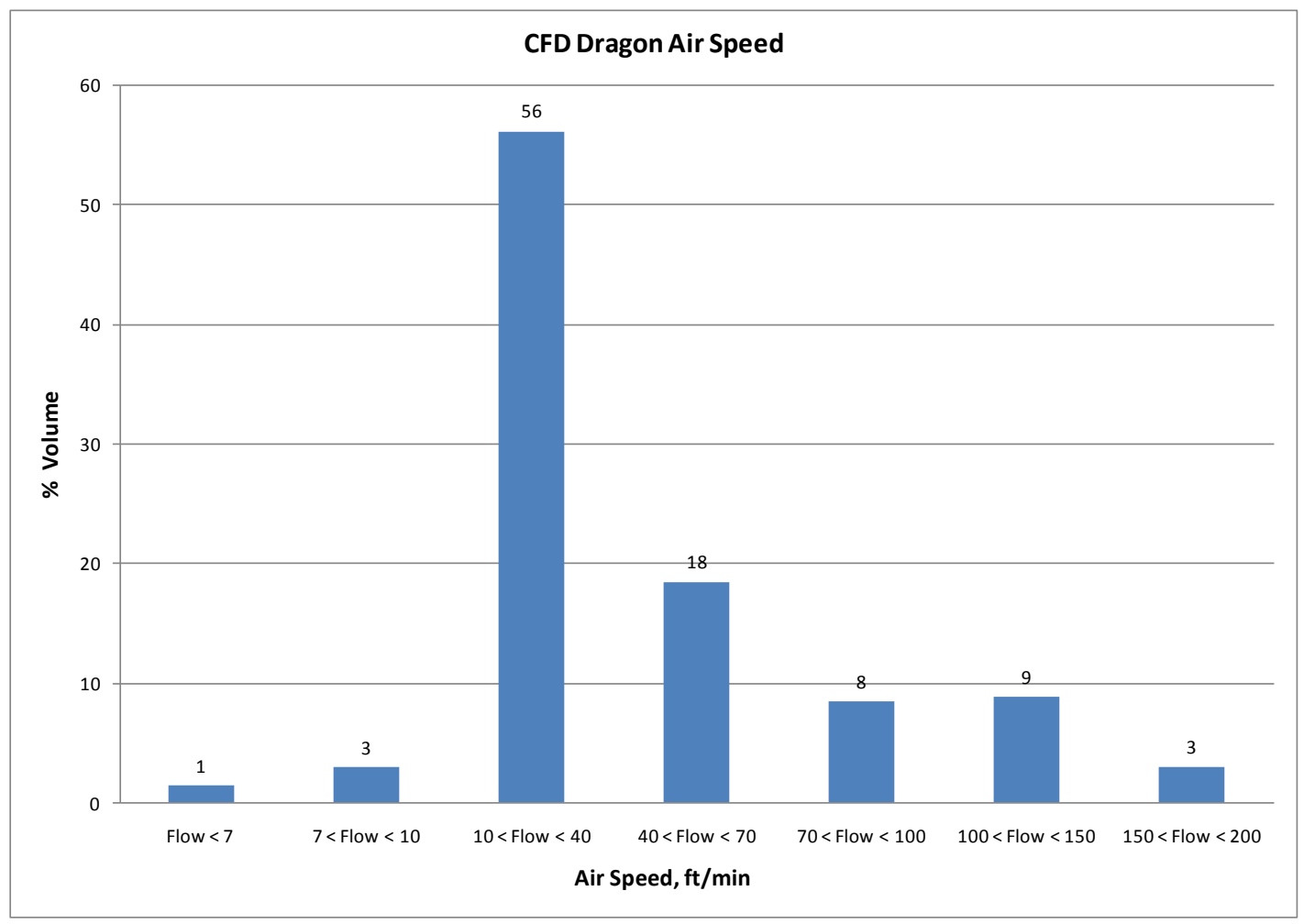

Figure 23.Volumetric air velocity distribution histogram

\section{F. Acoustics Development Test}

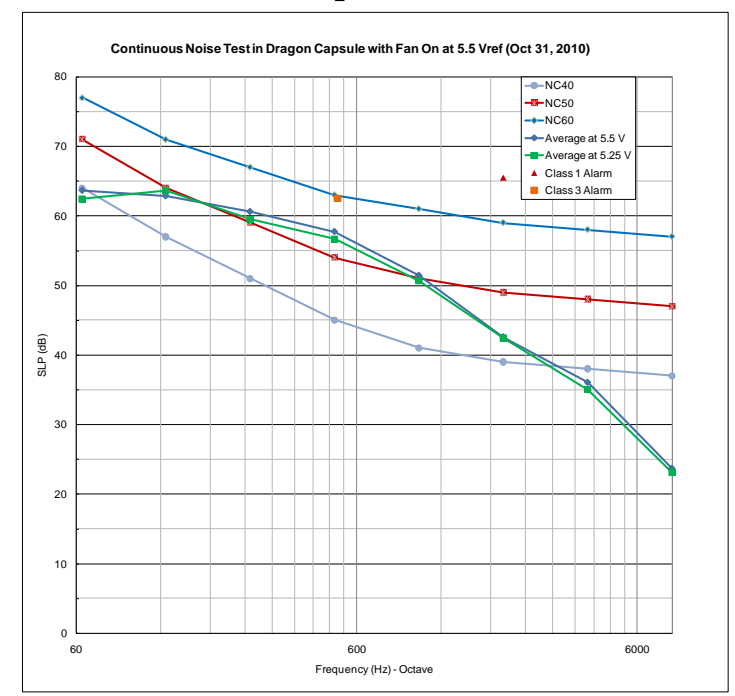

Figure 24. Acoustic Test Measurements
As mentioned previously, the same test set-up that was used for the air circulation testing was used for the acoustics testing. Polyimide foam was used under the floor, on the capsule walls and to completely drape the duct. The acoustic treatment that was previously mentioned around the fan shroud and inlet was also included. The acoustic testing involved taking noise measurement inside the capsule with the fan on at the nominal speed. A sound level meter was used to measure noise at 6 locations: inside the port, aft, starboard, late load rack and at the center of the capsule at $3 \mathrm{ft}$ above the floor and one measurement at the center of the capsule at $5 \mathrm{ft}$ above the floor. These were all deemed location were an ISS crew could potentially be while unloading cargo. One octave measurements were taken at each of these locations and the average of these was taken to assess if the continuous noise requirement was met. Figure 24 shows the resultant average noise measurement. The measurements showed that the class 1 alarm for emergencies would be heard and although the NC-

13

American Institute of Aeronautics and Astronautics 
50 requirement is not met at $500 \mathrm{~Hz}$, the class 3 alarm would still be audible.

Measurements taken to determine the noise at $0.6 \mathrm{~m}$ from the IMV is a challenge since the background noise in the integration and test facility at SpaceX when all machinery, air blowers, and lights are turned off is at or above NC-40 at frequencies above $250 \mathrm{~Hz}$. The noise measured at $0.6 \mathrm{~m}$ from the IMV is required to be at or below NC40. In order to have a valid test the background noise needs to be at least $3 \mathrm{~dB}$ below NC-40. It would essentially require moving Dragon to a quite environment like a library or an anechoic chamber.

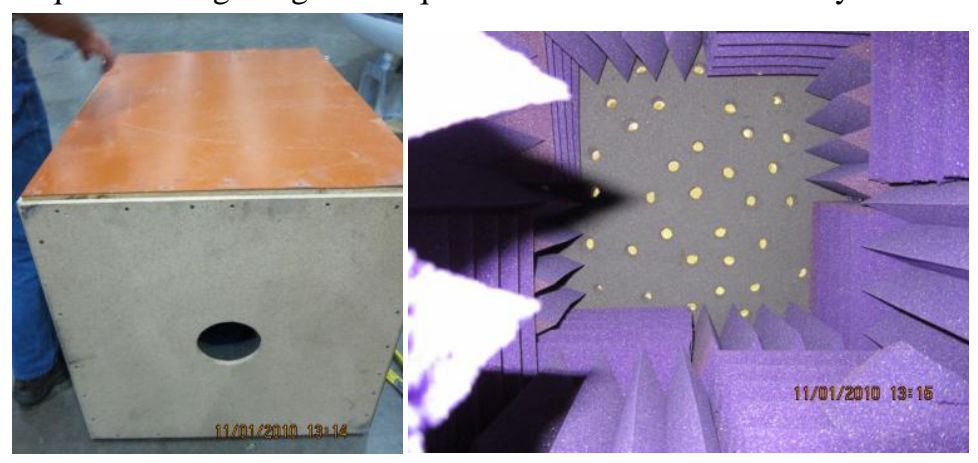

Figure 25. Anechoic Box to Take IMV Noise Measurements

To perform a test like this in an anechoic chamber would be very expensive and for this reason an anechoic like box was built to take this measurement locally at the IMV. The $3 \mathrm{ft}$ x $2 \mathrm{ft}$ x $2 \mathrm{ft}$ box made of 0.5 " wood and lined internally with 2 " of SoundCoat foam on the inside was used to reduce the background noise at the location that the IMV noise measurements were taken. SoundCoat foam was preferred to polyimide foam because it is 3 times denser. Additionally, to get reduced standing waves, 4" wedges of foam were added on top of the SoundCoat foam. The box has a hole for the IMV at the bottom of the box and forty 1" holes at the top of the box for air flow to the IMV and to insert the microphone and measure sound pressure level with the sound level meter. Figure 25 shows the interior \& exterior of the anechoic like box.

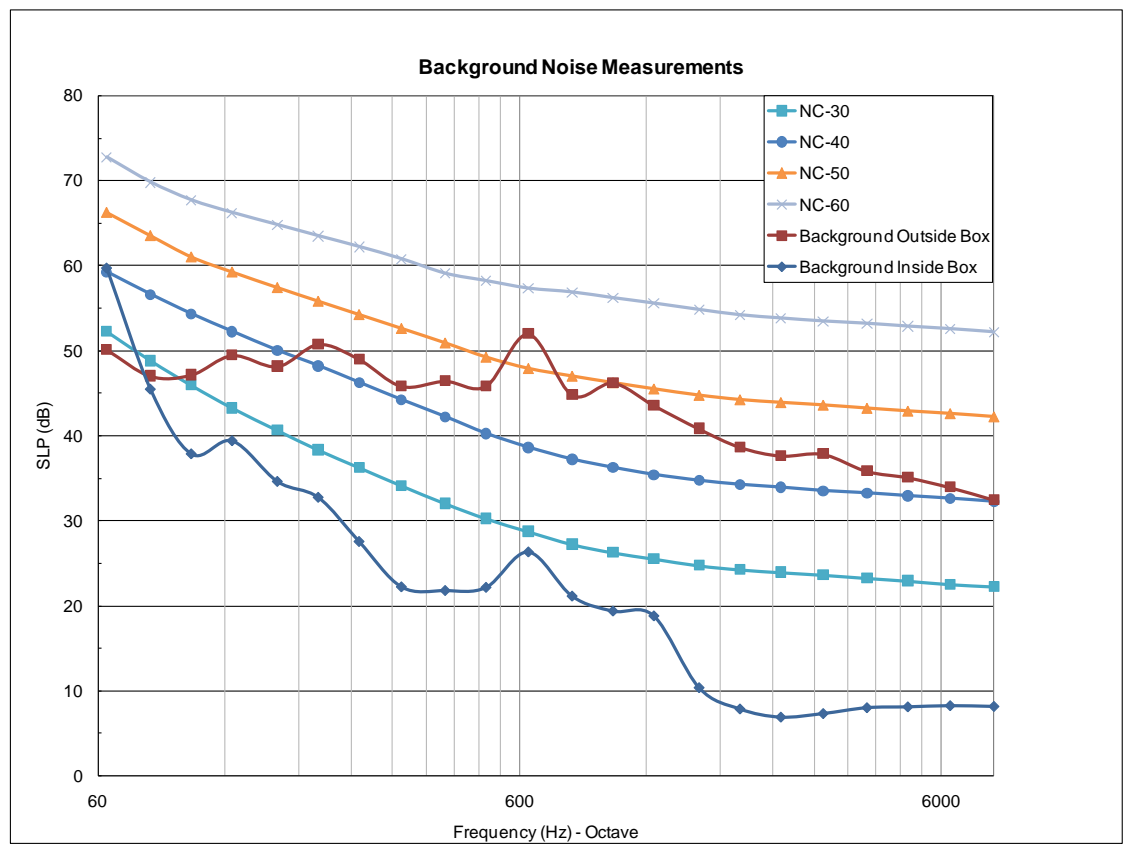

Figure 26. Background Noise Inside Anechoic Box
Figure 26 shows a plot of the background noise outside of the box and the background noise inside the box. The measurements of the background noise in the box shows that the sound pressure levels above $125 \mathrm{~Hz}$ are attenuated by $10 \mathrm{~dB}$ to $30 \mathrm{~dB}$ inside the box. Below 125 $\mathrm{Hz}$, the box does not attenuate noise. However, at frequencies below $125 \mathrm{~Hz}$, the background noise outside the box is below NC-30. Therefore, the box was used to measure the IMV noise at frequencies above $125 \mathrm{~Hz}$ only and below $125 \mathrm{~Hz}$ the IMV noise was measured without the box.

The IMV noise test showed that at the nominal fan speed the NC-40 requirement is met at all frequencies except at $125 \mathrm{~Hz}$ where it is exceeded by $4 \mathrm{~dB}$ (Figure 27). At $1000 \mathrm{~Hz}, \mathrm{NC}-40$ is exceeded by $2 \mathrm{~dB}$. Exceeding the $\mathrm{NC}-40$ by $2 \mathrm{~dB}$ is within measurement error. The $2 \mathrm{~dB}$ uncertainty includes instrumentation, repeatability, and human error (positioning). 


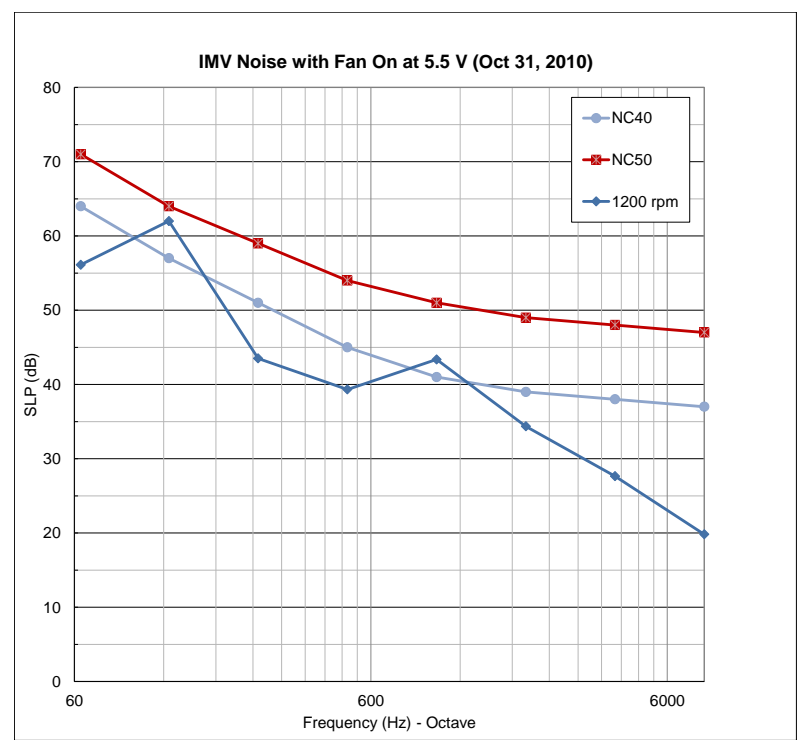

Figure 27. Noise Levels at the IMV 


\section{Conclusion}

The air circulation test and CFD results show that the ECS air circulation design meets the inter-vehicle requirements. The air speed spot checks show that the results predicted by the CFD model are comparable when taken in the same locations. Additionally, since the spot check and CFD are comparable, there is confidence in the CFD predictions and the model is considered correlated to the test data. The CFD model is now used for verification of air circulation inter and intra vehicle requirements.

Upon verification of the intra-vehicle circulation using the CFD, it was confirmed that atmosphere circulation requirement is met at low air speeds of $<7 \mathrm{ft} / \mathrm{min}$ since these make up only $3 \%$ of the cabin volume and the requirement is to have $<5 \%$ low air speeds $(<7 \mathrm{ft} / \mathrm{min}$ ) of the cabin volume. The air speeds between $10 \mathrm{ft} / \mathrm{min}$ and $40 \mathrm{ft} / \mathrm{min}$ make up $58 \%$ of the cabin volume, as opposed to the $67 \%$ requirement. However, this is due to the fact that the air speeds in the cabin are higher than required. Since the majority of the air speeds that are higher than 40 $\mathrm{ft} / \mathrm{min}$ are lower than $70 \mathrm{ft} / \mathrm{min}(20 \%)$, it is considered to be acceptable for crew comfort while at the same time provides plenty of air mixing to decrease the chances of stagnation pockets that could be hazardous to the crew. As mention previously, the American Society of Heating, Refrigeration and Air Conditioning Engineers (ASHRAE) standards for human comfort, the majority of humans are comfortable up to $250 \mathrm{ft} / \mathrm{min}$

Development acoustics testing showed that the IMV noise was acceptable at the nominal fan speed of $1200 \mathrm{rpm}$ since the significant exceedance to the NC-40 requirement was at $125 \mathrm{~Hz}$. In discussions with NASA, it was deemed acceptable because at this frequency there are no significant additional noises in Node 2 of ISS that would aggregate to this exceedance. A lower fan speed was assessed during the acoustics test to reduce continuous noise. The CFD was run at lower fan speeds as well for comparison at a fan speed of $1150 \mathrm{rpm}$ and $1100 \mathrm{rpm}$. The CFD results showed that by lowering the fan speed, the IMV and Powered Cargo air flow requirements would be marginally met. Since the alarms are still expected to be audible with the nominal fan speed of $1200 \mathrm{rpm}$, and lowering the fan speed would only lower the noise by $1 \mathrm{~dB}$ to $2 \mathrm{~dB}$, the fan speed of $1200 \mathrm{rpm}$ will be kept. The development tests showed that the air circulation design is acceptable from an acoustics stand point and provides sufficient air circulation.

\section{Acknowledgments}

The Dragon air circulation design, testing and development described in this paper was accomplished by the work and effort of many SpaceX engineers, designers, analysts, and technicians and by the knowledge and experiences that NASA ECLS shared about the ISS air circulation system.

\section{References}

${ }^{1}$ Francis, D., and Cox, B., "International Space Station Commercial Orbital Transportation Services Interface Document," NASA SSP 50808, 2009.

${ }^{2}$ Broyan, J., "International Space Station Crew Quarters Ventilation and Acoustic Design Implementation," AIAA International Conference on Environmental Control Systems, AIAA, Barcelona, Spain, 2010-6018. 